\title{
HUBUNGAN KARAKTERISTIK DAN DUKUNGAN TENAGA KESEHATAN DENGAN PERILAKU WANITA USIA SUBUR (WUS) TENTANG PEMERIKSAAN PAYUDARA SENDIRI (SADARI) UNTUK DETEKSI DINI KANKER PAYUDARA DI KELURAHAN BULUSTALAN KOTA SEMARANG
}

\section{RELATIONSHIP CHARACTERISTICS AND SUPPORT HEALTH WORKERS WITH FERTILE AGE WOMEN'S BEHAVIOR (WUS) ABOUT BREAST SELF EXAMINATION FOR EARLY DETECTION OF BREAST CANCER IN KELURAHAN BULUSTALAN SEMARANG}

\author{
Novita Nining Anggraini \\ Program Studi Diploma III Kebidanan Fakultas Ilmu Keperawatan dan Kesehatan Universitas \\ Muhammadiyah Semarang \\ Email : novitanovi@unimus.ic.id
}

\begin{abstract}
ABSTRAK
Masalah kanker payudara ditandai dengan masih tingginya angka kematian yang disebabkan paling utama oleh karena keterlambatan diagnosa, diikuti keterlambatan pengobatan. Keterlambatan diagnosa lebih disebabkan oleh karena kedatangan pasien di rumah sakit pada stadium lanjut. Beberapa data menunjukkan bahwa lebih dari 50\% pasien datang dalam stadium lanjut (Stage III dan IV). Risiko kanker payudara akan semakin meningkat dengan bertambahnya usia. Usia termuda untuk terjadinya kanker payudara adalah usia 10 - 14 tahun dan peningkatan prevalensi kanker payudara terjadi pada kelompok usia kurang dari 45 tahun dan Masa inkubasi masa kanker payudara diperkirakan 8-12 tahun. Tujuan dari penelitian ini untuk mengetahui berhubungan karakteristik dan dukungan tenaga kesehatan dengan perilaku SADARI untuk deteksi dini kanker payudara pada wanita usia 20-40 tahun di Kelurahan Bulustalan Kota Semarang. Jenis penelitian adalah deskriptif korelasi. penelitian deskriptif kuantitatif dengan pendekatan cross sectional. Variabel bebas adalah karakteristik umur dan pendidikan dan sebagai variabel terikat adalah perilaku wanita terhadap parktik SADARI. Sebanyak 104 wanita usia 20 - 40 tahun yang menjadi sampel penelitian. Pengumpulan data menggunakan angket. Analisis data secara univariat dan bivariat dengan uji statistik chi square. Tidak ada hubungan yang signifikan dengan perilaku SADARI ( $p$ value 0,202 dan hasil uji chi square dengan $C I=95 \%$ p value $>(0,05)$ tidak ada hubungan yang signifikan terhadap perilaku SADARI dengan $p$ value 0,096 dan hasil uji chi square dengan $C I=95 \% p$ value $>(0,05)$, tidak ada hubungan yang signifikan antara dukungan tenaga kesehatan dengan perilaku SADARI, $p$ value 0,113.
\end{abstract}

Kata Kunci : umur, pendidikan,dukungan tenaga kesehatan, perilaku SADARI

\begin{abstract}
The problem of breast cancer with the highest mortality rate due to late diagnosis, after taking the drug. Delay in diagnosis is more due to the presence of patients in the hospital at an advanced stage. Some data show more than 50\% of patients come in advanced stage (stage III and IV). The risk of breast cancer will increase with age. The youngest age for breast cancer flight is aged $10-14$ years and increased prevalence of breast cancer at age less than 45 years and incubation period of breast cancer 8-12. The purpose of the study to determine the diseases and diseases that occur in women aged 20-40 years in Bulustalan urban Semarang. The type of research is descriptive. Quantitative descriptive research with cross sectional approach. The independent variable is the characteristic of age and education and as the dependent variable is the female behavior on PARADAL PARK. A total of 104 women aged 20-40 years who became the sample of the study. Data collection using questionnaires. Univariate and bivariate data analysis with chi square statistic test. Result: no significant correlation with BSE behavior ( $p$ value 0,202 and chi square test with $C I=95 \% p$ value $>$ $(0,05)$ no significant correlation to behavior of BSE with $p$ value 0,096 and chi square test result with $C I=95 \% p$ value $>(0,05)$, there is no significant correlation between health and behavior of BSE, $p$ value 0,113 .
\end{abstract}

Keywords: age, education, health support, BSE behavior 


\section{PENDAHULUAN}

Kanker payudara merupakan masalah kesehatan masyarakat yang penting. Jumlah penderita Kanker di Kota Semarang masih dianggap tinggi oleh Kepala Dinas Kesehatan Kota Semarang. Meski dari data yang di paparkan jumlah penderita kanker di Semarang dari tahun ke tahun semakin menurun.

Masalah kanker payudara ditandai dengan masih tingginya angka kematian yang disebabkan paling utama oleh karena keterlambatan diagnosa, diikuti keterlambatan pengobatan. Keterlambatan diagnosa lebih disebabkan oleh karena kedatangan pasien di rumah sakit pada stadium lanjut. Beberapa data menunjukkan bahwa lebih dari $50 \%$ pasien datang dalam stadium lanjut (Stage III dan IV). Risiko kanker payudara akan semakin meningkat dengan bertambahnya usia. Usia termuda untuk terjadinya kanker payudara adalah usia $10-14$ tahun dan peningkatan prevalensi kanker payudara terjadi pada kelompok usia kurang dari 45 tahun dan Masa inkubasi masa kanker payudara diperkirakan 8-12 tahun.

Profil kesehatan kota tahun 2015 kasus kanker payudara sebesar 645 kasus, kasus kanker ditahun 2015 ini mengalami penurunan yang signifikan dibanding tahun-tahun sebelumnya. Pada tahun 2013 sebanyak 832 kasus, tahun 2014 sebanyak 1157 kasus dan tahun 20141157 kasus. Kasus kanker payudara menduduki peringkat utama dibandingkan dengan kasus kanker yang lain.

Dukungan tenaga kesehatan sangat diperlukan unrtuk mensosialisasikan SADARI di masyarakat sebagai bentuk kepedulian pemerintah terhadap kesehatan wanita terutama pencegahan kanker payudara. Jumlah pasien akan meningkat drastis bila kita tidak berbuat untuk pencegahan, Untuk itu dengan adanya kegiatan sosialisasi ini agar dapat di perhatikan dan di implementasikan sehingga dapat menurunkan penderita kanker tingkat lanjut menjadi tingkat dini. Jika wanita menjadi familiar terhadap payudaranya dengan melakukan SADARI secara rutin maka dia akan lebih mudah mendeteksi keabnormalan pada payudaranya sejak awal atau mengetahui bahwa penemuanya adalah normal atau tidak berubah selama bertahun - tahun.

studi pendahuluan di kelurahan Bulustalan dengan bebrapa wanita, dimana kelurahan tersebut mempunyai kasus kanker payudara terbanyak diantara kelurahan yang lain rata-rata mengatakan dukungan tenaga kesehatan sangat kurang tentang sosialisai SADARI.

\section{METODE PENELITIAN}

Jenis penelitian adalah deskriptif korelasi. penelitian deskriptif kuantitatif dengan pendekatan cross sectional. Variabel bebas adalah karakteristik umur dan pendidikan dan sebagai variabel terikat adalah perilaku wanita terhadap parktik SADARI. Sebanyak 104 wanita usia $20-40$ tahunyang menjadi sampel penelitian. Pengumpulan data dilakukan menggunakan angket Analisis data dilakukan secara univariat ( distribusi frekuensi) dan analisis bivariat (tabel silang dan uji statistik chi square). Alat pengumpul menggunakan kuesioner, untuk itu perlu diuji di lapangan. Populasi yang digunakan dalam penelitian ini adalah seluruh wanita di kelurahan Bulustalan usia $20-40$ tahun. . Jumlah sampel yang digunakan dalam penelitan ini berdasarkan kriteria eksklusi dan inklusi melalui penjaringan faktor resiko terlebih dahulu dari total populasi yang ada yakni 423 wanita, 
kemudian diberikan kuesioner yang berisi faktor resiko dan didapatkan sampel 104 responden. Analisa yang dilakukan terhadap tiap variabel dari hasil penelitian dalam analisis ini hanya menghasilkan distribusi dan persentase dari tiap variabel yang diteliti. Setalah itu menggunakan analisa bivariat dengan menggunakan $\mathrm{X}^{2}$ (chisquare). (Sugiyono, 2012; h.231).

\section{HASIL DAN PEMBAHASAN}

Dalam melakukan penelitian di kelurahan Bulustalan dengan menggunakan kuesioner, sebanyak 104 responden diperoleh hasil penelitian sebagai berikut:

1. Analisa Univariat

\section{a. Umur responden}

Tabel .1 Distribusi Frekuensi berdasarkan umur responden

\begin{tabular}{cccc}
\hline $\mathrm{N}$ & Kelompok & $\mathrm{N}$ & $(\%)$ \\
\hline 1 & Muda $(\leq 30$ th & 38 & 36,5 \\
\hline 2 & Dewasa $(>30$ & 66 & 63,5 \\
\hline & Jumlah & 104 & 100 \\
\hline
\end{tabular}

Tabel 1 menunjukan bahwa usia responden terbanyak adalah kategori dewasa (63,5\%), dibanding pada kelompok usia muda $(36,5 \%)$.

\section{b. Pendidikan responden}

Pendidikan responden digambarkan dalam tabel 4.3 berikut.

Tabel 2 Distribusi frekuensi responden berdasarkan pendidikan

\begin{tabular}{clcc}
\hline No & \multicolumn{1}{c}{ Pendidikan } & N & $\%$ \\
\hline 1 & $\begin{array}{l}\text { Menengah ke atas ( } \\
\text { SLTA,Akademi/Perg } \\
\text { uruan Tinggi) }\end{array}$ & 76 & 73,1 \\
\hline 2 & $\begin{array}{l}\text { Dasar ( SD, MI, } \\
\text { SLTP ) }\end{array}$ & 28 & \\
\hline & Total & 104 & 100,0 \\
\hline
\end{tabular}

Tabel 2 menunjukan bahwa mayoritas responden terbanyak adalah berpendidikan menengah ke atas $(73,1 \%)$, dibanding responden yang berpendidikan dasar $(26,9 \%)$.

\section{c. Dukungan Tenaga Kesehatan}

Dukungan Tenaga Kesehatan digambarkan dalam tabel 3 berikut.

Tabel 3 Distribusi frekuensi responden berdasarkan dukungan tenaga kesehatan

\begin{tabular}{llcc}
\hline No & \multicolumn{1}{c}{$\begin{array}{c}\text { Dukungan tenaga } \\
\text { kesehatan }\end{array}$} & N & $\%$ \\
\hline 1 & Mendukung ( Skor $\geq 6$ ) & 68 & 65,4 \\
\hline 2 & $\begin{array}{l}\text { Tidak Mendukung ( Skor } \\
<6)\end{array}$ & 36 & 34,6 \\
\hline & Total & 104 & 100,0 \\
\hline
\end{tabular}

Tabel 3 menunjukan bahwa mayoritas responden mendapatka dukungan dari petugas kesehatan $(65,4 \%)$, dibanding responden yang tidak mendapatkan dukungan dari tenaga kesehatan (34,6\%).

\section{d. Perilaku SADARI}

Perilaku SADARI digambarkan dalam tabel 4 berikut

Tabel 4 Distribusi frekuensi responden berdasarkan perilaku SADARI

\begin{tabular}{clcc}
\hline No & Perilaku SADARI & N & $\%$ \\
\hline 1 & Baik ( Skor $\geq 20)$ & 53 & 51,0 \\
\hline 2 & $\begin{array}{l}\text { Kurang baik ( Skor } \\
<20)\end{array}$ & 51 & 49,0 \\
\hline & & 104 & 100,0 \\
\hline
\end{tabular}

Tabel 4 menunjukan bahwa mayoritas responden memiliki perilaku SADARI yang baik $(51,0 \%)$, dibanding responden yang memiliki perilaku SADARI yang kurang baik (49,0\%). 


\section{Analisa Bivariat}

a. Hubungan antara umur dengan perilaku SADARI

Tabel 5 Tabulasi silang antara umur dengan perilaku SADARI

\begin{tabular}{|c|c|c|c|c|c|c|c|}
\hline \multirow[t]{3}{*}{ No } & \multirow[t]{3}{*}{ Umur } & \multicolumn{4}{|c|}{ Perilaku SADARI } & \multirow{2}{*}{\multicolumn{2}{|c|}{ Total }} \\
\hline & & \multicolumn{2}{|c|}{ Baik } & \multicolumn{2}{|c|}{$\begin{array}{c}\text { Kurang } \\
\text { baik }\end{array}$} & & \\
\hline & & $\mathrm{N}$ & $\%$ & $\mathrm{~N}$ & $\%$ & $\mathrm{~N}$ & $\%$ \\
\hline 1 & Muda & 23 & 60,5 & 15 & $\begin{array}{c}39, \\
5\end{array}$ & 38 & $\begin{array}{l}100, \\
0\end{array}$ \\
\hline 2 & $\begin{array}{l}\text { Dewas } \\
\text { a }\end{array}$ & 30 & 45,5 & 36 & $\begin{array}{c}54, \\
5\end{array}$ & 36 & 100,0 \\
\hline \multicolumn{8}{|c|}{$P$ value $=0,202$} \\
\hline
\end{tabular}

Tabel 5 menjelaskan responden yang berperilaku SADARI kurang baik yang mempunyai umur kategori dewasa $(54,5 \%)$ lebih besar daripada kategori muda $(39,5 \%)$. Responden yang berperilaku SADARI baik yang mempunyai umur kategori muda (60,5\%) lebih besar daripada kategori dewasa (45,5\%). Hasil uji chi square menunjukkan $p$ value $(0,202)$ lebih besar dari taraf signifikan $(0,05)$ sehingga Ho diterima. Dengan demikian, tidak ada hubungan signifikan antara umur responden dengan perilaku SADARI.

Pada penelitian ini melibatkan responden dengan usia muda yaitu $\leq 30$ tahun dan usia dewasa yaitu $>30$ tahun. Proporsi jumlah usia responden terbanyak ada pada usia dewasa $(63,5 \%)$, sedangkan kelompok usia muda sebanyak $(36,5 \%)$.

Dari hasil analisa bivariat menunjukan bahwa variabel ini merupakan variabel yang tidak mempunyai hubungan yang signifikan dengan perilaku SADARI ( $p$ value 0,202 dan hasil uji chi square dengan $\mathrm{CI}=95 \% \mathrm{p}$ value $>(0,05)$ artinya bahwa responden dengan usia muda dengan perilaku SADARI yang kurang baik lebih sedkit dibandingkan dengan usia dewasa dengan perilaku SADARI yang kurang baik lebih banyak.

\section{b. Hubungan antara pendidikan dengan perilaku SADARI \\ Tabel 6 Tabulasi silang antara pendidikan dengan perilaku SADARI}

\begin{tabular}{|c|c|c|c|c|c|c|c|}
\hline \multirow[t]{3}{*}{ No } & \multirow[t]{3}{*}{ Pendidikan } & \multicolumn{4}{|c|}{ Perilaku SADARI } & \multirow{2}{*}{\multicolumn{2}{|c|}{ Total }} \\
\hline & & \multicolumn{2}{|c|}{ Baik } & \multicolumn{2}{|c|}{$\begin{array}{c}\text { Kurang } \\
\text { baik }\end{array}$} & & \\
\hline & & $\mathrm{N}$ & $\%$ & $\mathrm{~N}$ & $\%$ & $\mathrm{~N}$ & $\%$ \\
\hline 1 & $\begin{array}{l}\text { Menengah } \\
\text { ke atas }\end{array}$ & 43 & 56,6 & 33 & $\begin{array}{c}43 \\
3\end{array}$ & 76 & $\begin{array}{l}100, \\
0\end{array}$ \\
\hline 2 & Dasar & 10 & 35,7 & 18 & $\begin{array}{c}64, \\
3 \\
\end{array}$ & 28 & $\begin{array}{l}100, \\
0\end{array}$ \\
\hline \multicolumn{8}{|c|}{$P$ value $=0,096$} \\
\hline
\end{tabular}

Tabel 6 menjelaskan responden yang berperilaku SADARI kurang baik yang mempunyai pendidikan kategori dasar $(64,3 \%)$ lebih besar daripada kategori menengah ke atas (43,3\%). Responden yang berperilaku SADARI baik yang mempunyai pendidikan kategori menengah ke atas $(56,6 \%)$ lebih besar daripada kategori dasar $(35,7 \%)$. Hasil uji chi square menunjukkan $p$ value $(0,096)$ lebih besar dari taraf signifikan $(0,05)$ sehingga Ho diterima. Dengan demikian, tidak ada hubungan signifikan antara pendidikan responden dengan perilaku SADARI.

Mayoritas responden terbanyak adalah berpendidikan menengah ke atas $(73,1 \%)$, dibanding responden yang berpendidikan dasar (26,9\%). Semakin tinggi pendidikan seseorang semakin mudah pula menyerap pengetahuan dan semakin mudah pula untuk melakukan praktik sesuai dengan pengetahuan yang didapat. Namun pada kenyataanya tidak terdapat hubungan antara pendidikan dengan perilaku SADARI.

Dan hasil analisa bivariat menunjukan bahwa pendidikan merupakan variabel yang secara statistik menunjukan tidak ada hubungan yang signifikan terhadap perilaku SADARI dengan $p$ value 0,096 dan hasil uji chi square dengan $\mathrm{CI}=95 \% \mathrm{p}$ value $>(0,05)$ artinya bahwa responden yang mempunyai pendidikan dasar ataupun menengah ke atas tidak menunjukkan kecenderungan untuk melakukan perilaku SADARI. 


\section{c. Hubungan antara dukungan tenaga kesehatan dengan perilaku SADARI Tabel 7 Tabulasi silang antara dukungan tenaga kesehatan dengan perilaku SADARI}

\begin{tabular}{|c|c|c|c|c|c|c|c|}
\hline \multirow[t]{3}{*}{ No } & \multirow{3}{*}{$\begin{array}{l}\text { Dukungan } \\
\text { tenaga } \\
\text { kesehatan }\end{array}$} & \multicolumn{4}{|c|}{ Perilaku SADARI } & \multicolumn{2}{|c|}{ Total } \\
\hline & & \multicolumn{2}{|c|}{ Baik } & \multicolumn{2}{|c|}{ Kurang baik } & & \\
\hline & & $\mathrm{N}$ & $\%$ & $\mathrm{n}$ & $\%$ & $\mathrm{~N}$ & $\%$ \\
\hline 1 & $\begin{array}{l}\text { Menduku } \\
\text { ng }\end{array}$ & 39 & 57,4 & 29 & 42,6 & 68 & $\begin{array}{l}100 \\
, 0\end{array}$ \\
\hline 2 & $\begin{array}{l}\text { Tidak } \\
\text { mendukun } \\
\text { g }\end{array}$ & 14 & 38,9 & 22 & 61,1 & 36 & $\begin{array}{l}100 \\
, 0\end{array}$ \\
\hline
\end{tabular}

Tabel 4.27 menjelaskan responden yang berperilaku SADARI kurang baik yang tidak memperoleh dukungan tenaga kesehatan (61.1\%) lebih besar daripada yang memperoleh dukungan $(42,6 \%)$. Responden yang berperilaku SADARI baik yang memperoleh dukungan tenaga kesehatan $(57,4 \%)$ lebih besar daripada yang tidak memperolah dukungan (38,9\%). Hasil uji chi square menunjukkan $p$ value $(0,113)$ lebih besar dari taraf signifikan $(0,05)$ sehingga Ho diterima. Dengan demikian, tidak ada hubungan signifikan antara dukungan tenaga kesehatan dengan perilaku SADARI.

Hasil uji statistik dengan chi square menyimpulkan bahwa tidak ada hubungan yang signifikan antara dukungan tenaga kesehatan dengan perilaku SADARI, $p$ value 0,113, dimana responden yang berperilaku SADARI baik yang memperoleh dukungan tenaga kesehatan (57,4\%) lebih besar daripada yang tidak memperolah dukungan (38,9\%). Responden yang berperilaku SADARI kurang baik yang tidak memperoleh dukungan tenaga kesehatan (61.1\%) lebih besar daripada yang memperoleh dukungan (42,6\%). Hal ini berarti bahwa dukungan tenaga kesehatan tidak serta merta mempengaruhi responden untuk melakukan SADARI. Dukungan Petugas sangat membantu, dimana dengan adanya dukungan petugas dari petugas sangatlah besar artinya bagi seseorang dalam melakukan praktik SADARI, motivasi atau dukungan yang diberikan petugas sangat besar artinya terhadap ketaatan pesien untuk selalu melakukan praktik SADARI secara rutin

\section{KESIMPULAN}

1. Tidak ada hubungan yang signifikan dengan perilaku SADARI ( $p$ value 0,202 dan hasil uji chi square dengan $\mathrm{CI}=95 \%$ v value $>(0,05)$

2. Tidak ada hubungan yang signifikan terhadap perilaku SADARI dengan $p$ value 0,096 dan hasil uji chi square dengan $\mathrm{CI}=95 \% p$ value $>$ $(0,05)$

3. Tidak ada hubungan yang signifikan antara dukungan tenaga kesehatan dengan perilaku SADARI, $p$ value 0,113 .

\section{DAFTAR PUSTAKA}

Atmodjo S. 2007. Promosi Kesehatan dan Ilmu Perilaku. Rineka Cipta. Jakarta

Arikunto dan Suharsimi. 2006. Prosedur Penelitian Suatu Pendekatan Praktek. Rineka Cipta. Jakarta.

Dinas Kesehatan Kota Semarang. 2014. Profil Kesehatan Kota Semarang. Dinas Kesehatan Kota Semarang. Semarang.

Direktorat Jenderal Pengendalian Penyakit dan Penyehatan Lingkungan Direktorat Pengendalian Penyakit Tidak Menular. 2010. Buku Saku Pencegahan Kanker Payudara \& Kanker Leher Rahim. Kementerian Kesehatan RI. Jakarta.

Handayani DS. 2008. Hubungan antara Tingkat Pengetahuan dan Sikap dengan Perilaku para Wanita Dewasa Awal dalam Melakukan Pemeriksaan Payudara Sendiri di 
Kelurahan Kalangan Kecamatan Pedan Klaten (Tesis). Magister Keperawatan Fakultas Kedokteran Universitas Diponegoro. Semarang. Mubarak WI. 2007. Promosi Kesehatan Sebuah Pengantar Proses Belajar Mengajar dalam Pendidikan. Graha Ilmu.Yogyakarta.

Notoatmodjo S. 2010. Metodologi Penelitian Kesehatan. Rineka Cipta. Jakarta.

Notoatmodjo S. 2010. Konsep Perilaku Kesehatan: Dalam Promosi Kesehatan Teori \& Aplikasi (Edisi revisi). Rineka Cipta. Jakarta.

Notoatmodjo S. 2003. Pendidikan dan Perilaku Kesehatan. Rineka Cipta. Jakarta.

Prawirohardjo S. 2009. Ilmu Kandungan. Bina Pustaka. Jakarta.

Ramli M. Deteksi Dini Kanker. Fakultas Kedokteran Universitas Indonesia. Jakarta.

Rasjidi I. 2010. 100 Questions and Answers: Kanker pada Wanita. Gramedia. Jakarta.

Republik Indonesia. Keputusan Menteri Kesehatan

No.796/Menkes/SK/VII/2010. 2012. Pedoman Teknis Pengendalian Kanker Payudara dan Kanker Leher Rahim. Sekretaris Negara. Jakarta.

Sarwono dan Jonathan. 2006. Metode Penelitian Kuantitatif dan Kualitatif. Graha Ilmu.Yogyakarta.

Sarwono. 2008. Ilmu Kebidanan. Yayasan Bina Pustaka Sarwono Prawirohardjo. Jakarta.

Sugiyono. 2002. Statistika untuk Penelitian. Alfabeta. Bandung.

Suparyanto. 2013. Pemeriksaan Payudara Sendiri. Aura Medika. Jakarta.

Supit N. 2005. Deteksi Dini Keganasan Payudara dalam Deteksi Dini Kanker. Fakultas Kedokteran Universitas Indonesia. Jakarta.

World Health Organization (WHO). Latest World Cancer Statistics Global Cancer Burden Rises to 14.1 Million New Cases in 2012: Marked Increase in Breast Cancers Must be Addressed. Diakses dari https://www.who.int/mediacentre. Pada tanggal 3 Maret 2013. 